\title{
Effectiveness of a novel ozone and hydrogen peroxide gas-vapour system for the rapid high level disinfection of surfaces and healthcare
} spaces

\author{
D Zoutman ${ }^{1 *}$, M Shannon², K Brown ${ }^{2}$ \\ From International Conference on Prevention \& Infection Control (ICPIC 2011) \\ Geneva, Switzerland. 29 June - 2 July 2011
}

\section{Introduction / objectives}

Vapour based fumigant systems for disinfection of healthcare surfaces and spaces are an evolving technology. A new system that uses an ozone based process to create a highly reactive oxidative gas-vapour mixture that is noncorrosive was tested in vitro and in vivo for antimicrobial disinfection effectiveness.

\section{Methods}

Ozone gas at 80 parts per million (ppm) was combined with $1 \%$ stabilized hydrogen peroxide vapour at $80 \%$ relative humidity in a test chamber and upscaled to a 82 cubic meter room using $3.75 \%$ hydrogen peroxide at 30 minutes. Test organisms included methicillin resistant $S$. aureus, vancomycin resistant Enterococcus, E. coli, P. aeruginosa, and $C$. difficile spores dried onto stainless steel discs.

\section{Results}

The combination of $80 \mathrm{ppm}$ ozone with $1 \%$ hydrogen peroxide vapour in the test chamber achieved a very high level of disinfection of at least $6 \log _{10}$ reduction of the bacteria and $C$. difficile spores tested on steel discs during a 15 minute exposure. The entire system was scalable such that it achieved the same high level of disinfection of an 81 cubic meter room in 30 minutes with $3.75 \%$ hydrogen peroxide and 80 PPM of ozone against MRSA and C. difficile spores.

\section{Conclusion}

The ozone and hydrogen peroxide gas-vapour mixture provides a very rapid and high level of disinfection of steel surfaces against important healthcare associated bacterial pathogens. The system is an advanced oxidative process providing a rapid and effective means to disinfect healthcare surfaces and spaces to a very high level, particularly against $C$. difficile spores.

\section{Disclosure of interest}

D. Zoutman Grant/Research support from Medizone International Inc, Shareholder of Medizone International Inc, M. Shannon Employee of Medizone International Inc, Shareholder of Medizone International Inc, K. Brown Employee of Medizone International Inc.

\section{Author details}

${ }^{1}$ Medical Microbiology, Queen's University, Ontario, Canada. ${ }^{2}$ Medizone International Inc, Kingston, Ontario, Canada.

Published: 29 June 2011

\section{doi:10.1186/1753-6561-5-S6-038}

Cite this article as: Zoutman et al:: Effectiveness of a novel ozone and hydrogen peroxide gas-vapour system for the rapid high level disinfection of surfaces and healthcare spaces. BMC Proceedings 20115 (Suppl 6):O38. 